\title{
UNA CONSIDERACIÓN ACTUAL SOBRE EL DEBER DE OBEDIENCIA AL DERECHO. LA JUSTIFICACIÓN DE SU INCUMPLIMIENTO POR RAZONES ÉTICAS
}

\author{
A consideration regarding the rule of law. \\ The justification of disobedience for ethical reasons
}

\author{
LAURA GÓMEZ ABEJA \\ Universidad de Sevilla \\ lgomez2@us.es
}

Cómo citar/Citation

Gómez Abeja, L. (2017).

Una consideración actual sobre el deber de obediencia al derecho. La justificación de su incumplimiento por razones éticas. Revista de Estudios Políticos, 177, 89-111. doi: https://doi.org/10.18042/cepc/rep.177.03

Resumen

El presente trabajo efectúa un breve repaso de las teorías más importantes que han reflexionado sobre las razones por las que el derecho debe obedecerse (dejando a un lado a los autores clásicos de la teoría del Estado, cuyas tesis no se desarrollarían todavía en el contexto de ordenamientos democráticos) y aborda a continuación los motivos que pueden justificar, en sentido contrario, la desobediencia frente a la obligación jurídica. A partir de la conclusión alcanzada, la existencia de una razón ética de obediencia al derecho democrático, el trabajo defiende la posible concurrencia de una razón moral individual — con más peso que la primera — que podría justificar el incumplimiento de la ley. Claro que no cualquier disidencia ideológica frente a la norma estará justificada, por más que concurran razones morales. Por ello se trata, para concluir, la postura que puede y debe adoptar el ordenamiento jurídico ante el incumplimiento éticamente motivado de la ley.

\section{Palabras clave}

Razón moral; obediencia; consentimiento; desobediencia civil. 


\begin{abstract}
This paper assesses the most important theories that have reflected on the reasons why the law must be obeyed (leaving aside the Theory of the State classical authors, as they did not develop their writings in the context of a democratic system). It also addresses the reasons that could justify disobeying the law. The paper argues that an ethical justification for obedience to the law exists in a democratic system. Following this, the article proposes the existence of an individual moral reason with more weight than the first, which may justify breaches of the law. Naturally, dissidence against the rule of law for ideological reasons is not always justified, even though moral reasons are involved. Thereby, to conclude the paper assesses the position the legal system can, and should, adopt, when confronted with an ethically motivated infringement of the law.
\end{abstract}

\title{
Keywords
}

Moral reason; obedience; consent; civil disobedience. 


\section{SUMARIO}

I. INTRODUCCIÓN. II. LA OBEDIENCIA AL DERECHO EN UN SISTEMA DEMOCRÁTICO: 1. El consentimiento como principal razón «moral» de obediencia a las normas democráticas. 2. Neocontractualismo y otras «razones morales» distintas del consentimiento. 3. La inexistencia de toda "razón moral» para obedecer el derecho democrático. III. LA JUSTIFICACIÓN DE LA DESOBEDIENCIA AL DERECHO EN UN ESTADO DEMOCRÁTICO: 1. Posiciones contrarias a la justificación de la desobediencia. 2. Justificación de la desobediencia por razones morales. 3. Precisiones conceptuales. IV. CONCLUSIONES. Biblografía.

\section{INTRODUCCIÓN}

Un clásico entre las cuestiones propias de la ciencia política es el de si existe un deber, más allá de la obligación propiamente jurídica, por el que hayan de obedecerse las leyes. La citada cuestión conduce a un segundo interrogante de indudable actualidad, el de si puede justificarse, en sentido contrario, la desobediencia frente a las normas jurídicas. Ambos extremos van en efecto de la mano, pues toda tesis tendente a justificar la desobediencia de las normas da por hecho la existencia de una obligación de obedecer el derecho (Passerin D'entreves, 1976: 28).

Se trataría, claro está, de una obligación más allá de la exigida por la propia norma, por cuanto el carácter coercitivo del deber jurídico no basta per se para garantizar su observancia, al menos con carácter general. Se ha afirmado, en este sentido, que el deber de obedecer la norma no puede consistir solamente en la propia obligación legal, pues al derivar esta siempre de una ley, «tendría que haber una ley que dijese que debemos obedecer la ley. ¿Qué obligación habría, entonces, de obedecer esa ley?» (Singer, 1985: 11).

El acatamiento de la norma, por tanto, solamente en parte se explica por su carácter coactivo. La capacidad del Estado para imponer sus normas por la fuerza es muy reducida, por más que sea cierto que detrás de cada una de ellas, individualmente, se encuentre el aparato coactivo estatal para aplicarla. Según diversos estudios efectuados desde la sociología jurídica, en un Estado cuyo procedimiento coercitivo funcionase a la perfección, solamente podría imponerse por la fuerza menos de un $10 \%$ de sus leyes, por lo que puede afirmarse que «el ordenamiento jurídico del Estado tiene necesidad de la coacción para 
mantenerse, pero no puede descansar en la coacción» (Pérez Royo, 2014: 77; véase también Pérez Luño, 1991: 382).

Es aceptado de forma casi unánime entre quienes se han aproximado a esta cuestión que existe otra razón por la que acatamos los deberes impuestos por la norma. Junto a la obligación legal que se deriva de la misma, existe una obligación moral de acatamiento, siempre que la norma forme parte de un sistema democrático. Los rasgos propios de un orden democrático le proporcionan un valor objetivo, a tal punto que la vinculación a las normas emanadas del mismo por parte de sus destinatarios adquiere una naturaleza moral. Dicho de otro modo, el obligado por la norma lo estaría no ya, o no solo, por la eventual sanción prevista para el caso de incumplimiento, sino porque tiene en última instancia razones morales para cumplirla.

Ahora bien, este deber moral no sería una obligación absoluta, sino solo prima facie, respecto de la que podrían producirse excepciones. Nos situaríamos así en el ámbito de la desobediencia al derecho y su posible justificación, aunque un análisis ordenado de las cuestiones que nos ocupan aconseja reflexionar primero sobre la propia existencia de esa supuesta obligación moral, efectuando una revisión de las más conocidas teorías que la justifican y los motivos en que fundamentan este deber de acatamiento.

\section{LA OBEDIENCIA AL DERECHO EN UN SISTEMA DEMOCRÁTICO}

\section{EL CONSENTIMIENTO COMO PRINCIPAL RAZÓN «MORAL» DE OBEDIENCIA A LAS NORMAS DEMOCRÁTICAS}

Las primeras tesis tendentes a justificar el acatamiento de las normas se desarrollan desde la más temprana andadura del Estado como forma de organización política. Autores clásicos como Locke, Rousseau o Kant abordarían la cuestión al tratar de justificar la legitimación del poder en los albores del Estado, defendiendo el carácter absoluto de las razones para la sumisión a sus normas. Es, pues, en el contexto de ruptura con el Antiguo Régimen donde surgen los primeros autores contractualistas que buscan explicar las razones por las cuales, ante el nuevo horizonte de libertad, los individuos deben someterse al también nuevo orden jurídico.

A través de la idea del conocido contrato social se buscaría, en palabras de Rousseau (2004: libro II, cap. VI, 55), «encontrar una forma de asociación que defienda y proteja de toda fuerza común a la persona y a los bienes de cada asociado, y mediante la cual cada uno, uniéndose a todos los demás, no 
obedezca sino a sí mismo y quede tan libre como antes». De esta ficción devendría un total sometimiento al pacto social y a sus leyes ${ }^{1}$.

Ya en el contexto de un sistema democrático, la doctrina científica actual justifica también el deber de acatamiento del derecho en la adhesión de los gobernados al sistema y a las normas emanadas del mismo. Claro que estas tesis más recientes, desarrolladas en ordenamientos propiamente democráticos, parten de las insuficiencias del contractualismo y ninguna pretende ya contar con el consentimiento (real) de todos los ciudadanos en las decisiones que emanan del poder legítimo. Siendo así, por una parte se matiza el modo de otorgar el consentimiento y su alcance y, por otra, se proporcionan otros argumentos distintos para justificar el deber de obediencia.

Conviene huir, de hecho, de una clasificación estricta de las teorías que actualmente justifican la obediencia al derecho, pues estas en ningún caso constituyen compartimentos estancos, sino que ostentan una posición ecléctica, sustentando sobre motivos diversos el deber de obediencia. Sucede que se las categoriza atendiendo al elemento en el que hacen especial hincapié, considerando que se trata, por ejemplo, de teorías consensualistas, teleológicas o utilitaristas, si inciden en especial, respectivamente, en la tendencia al consenso, en el hecho de que persigan un fin justo, o, por último, en el beneficio que el cumplimiento de las normas reporte.

Sea como fuere, para la mayor parte de la doctrina científica uno de los motivos - no el único - para el cumplimiento de las normas es que se trata de un sistema que tiende al consenso. En realidad, de conformidad con cuanto antecede, la consideración de una teoría como propiamente consensualista dependerá de que, frente a otras razones para la obediencia, el acento se ponga especialmente en el consentimiento.

Interesan en este sentido las teorías de Simmons o Plamenatz, que tratarían de abordar desde nuevas perspectivas la noción de consentimiento tácito planteada por Locke, y llegarían a la conclusión de que el mismo no puede constituir la única razón que justifique el acatamiento de las normas. Simmons, en concreto, defendería que, en el Segundo Tratado sobre el Gobierno Civil, Locke incluía tres tipos de actos que "cuentan» como consentimiento (Simmons, 1981: 75-95; 1976: 275) ${ }^{2}$ y que, en realidad, solamente el tercer tipo sería consentimiento stricto sensu, el «acto por el que se permite a otro un derecho especial de actuar en áreas en las que normalmente sólo el que

1 Según este autor (Rousseau, 2004: libro II, cap. VI, 86-87), «no hay que preguntar [...] si la ley puede ser injusta, puesto que nadie es injusto consigo mismo».

2 Simmons diferencia las promesas, los contratos escritos y los actos por los que se autoriza la actuación de un tercero. 
consiente es libre de hacerlo» (Simmons, 1976: 276; véase también Tussman, 1960: 36). Consecuentemente, en los Estados modernos solo una minoría habría otorgado a la autoridad política (tácitamente) su consentimiento, por lo que este únicamente obligaría a una reducida parte de la ciudadanía. Lo que antecede no significa que los tradicionalmente considerados implying-consent acts (como participar en unas elecciones) no sean generadores de un deber. Este tipo de actos también crea una obligación moral de acatamiento de las leyes, si bien por otras razones distintas del consentimiento.

Plamenatz, por su parte, pondría en cuestión la conocida afirmación del clásico autor según la cual «un hombre, por el simple hecho de viajar dentro de los territorios del rey de Inglaterra, está realmente, aunque de manera tácita, de acuerdo en obedecer sus leyes» (Plamenatz, 1970: 17). Para Plamenatz, con esta consideración Locke no hacía sino alterar la naturaleza del consentimiento (1970: 18). A su juicio, lo que genera la obligación moral de obediencia es la participación de los electores en el procedimiento democrático, pues es lo que los vincula a su resultado y a las normas que emanen del poder legítimo. Incluso quien vote en contra del partido o del candidato que resulte elegido a resultas del proceso electoral quedaría obligado por el deber de obediencia, por cuanto «si la elección fue libre y tomó parte en ella, consintió a la autoridad del hombre elegido" (1970: 153)3. También quienes se abstengan de votar en las elecciones de un sistema democrático quedan vinculados por la obligación moral, entrando entonces en juego el consentimiento tácito: los electores consienten tácitamente al aceptar el sistema político como un todo, «porque la posibilidad de votar cuenta como consentimiento cuando se han abstenido y no han manifestado al mismo tiempo su oposición al sistema cuando era fácil y posible hacerlo» (Gascón Abellán, 1990: 155). Con todo, es evidente que no "consienten» de igual modo los ciudadanos que voten a favor del ganador de las elecciones que los que lo hagan en contra o, sencillamente, no participen en dichas elecciones. Existirían, así, varios tipos de obligación moral, mayor para los primeros y más débil para el resto. Pero, nuevamente, existen otras razones morales que compensan la menor intensidad del deber en el caso de falta de aquiescencia.

3 Para este autor (Plamenatz, 1970: 151) el consentimiento implica «hacer o tomar parte en algo que el que lo hace sabe que crea en otro un derecho que no tendría de otra manera». En un sentido parecido, véase Partridge (1971: 35 y ss.).

4 Esta teoría de Plamenatz sobre el consentimiento y el voto es cuestionada por Siegler (1968: 261), que no cree que pueda deducirse del acto de votar el consentimiento de todos y cada uno de los ciudadanos, incluso aunque ello implique distintos niveles de obligación moral. 
La teoría de Singer (1985), en tercer lugar, también toma como referencia del deber de acatamiento de las normas el consentimiento de los obligados. De las diversas maneras en que un grupo de personas puede organizarse para tomar decisiones, concluye, únicamente cuando estas se sirvan de un procedimiento democrático resultarán moralmente obligadas a obedecer (Singer, 1985: $21-25)^{5}$, por cuanto solo entonces concurren dos razones para ello: el procedimiento implica un compromiso justo y la mera participación en el mismo crea esa obligación de obediencia (Singer, 1985: 69).

Para Singer, el consentimiento por sí solo no sería una explicación válida de la aceptación del procedimiento democrático de toma de decisiones ni del deber de acatar sus leyes, pues no puede sostenerse que la persona que nace en una sociedad estatal acepte dicha organización por el hecho de permanecer en ella, ni tampoco que quien participa en un sistema democrático votando en contra del candidato que gana las elecciones ha dado a esa persona su consentimiento para que gobierne ni, en fin, que quien se abstiene de participar en las elecciones consiente tácitamente su resultado. La tesis parte consecuentemente de una noción distinta, el cuasi consentimiento (Singer, 1985: 57) ${ }^{6}$, con el cual si bien no se produce formalmente aceptación del mecanismo de toma de decisiones ni de las normas que de él emanan, sí se dan ciertas circunstancias en las que «el comportamiento puede dar origen a una obligación de actuar como si hubiera consentimiento, aun cuando de hecho no lo haya" (Singer, 1985: 59) ${ }^{7}$. Esto es lo que sucedería al votar en las elecciones de un sistema democrático. La obligación de acatamiento no deriva ni depende del consentimiento real, sino del mero acto de participación en el procedimiento, que genera el deber de aceptar tanto el resultado del mismo como las ulteriores decisiones adoptadas por el poder legítimo (Singer, 1985: 59 y 63).

5 Según este autor (Singer, 1985: 11), una persona se conduce moralmente «toda vez que actúa ateniéndose a consideraciones que estaría dispuesta a hacer valer universalmente y que para ella son más importantes que cualesquiera otras consideraciones igualmente universales».

6 Con este concepto propio, el autor pretende superar las críticas de las que eran objeto las teorías puramente consensualistas.

7 El autor (Singer, 1985: 59) se sirve en este caso del siguiente ejemplo: «Un miembro del grupo invita a los demás a la primera ronda de bebidas, después otro hace lo mismo, y así sucesivamente. Si después de que la mayoría de los miembros del grupo hayan hecho esto, otro miembro que ha aceptado las anteriores invitaciones a beber se niega a invitar a los demás con otra ronda, los demás pensarán que se ha conducido mal. Se podría decir que tiene la obligación de invitar a beber a los demás. Esta obligación no se deriva de un consentimiento efectivo [...]. Sin embargo, al actuar de una manera determinada uno puede contraer una obligación» (cursivas añadidas). 
La mera participación determinaría, pues, que tanto los ciudadanos que votasen a favor del candidato o partido electo como los que lo hiciesen en contra quedarían obligados por el deber de obediencia, pero no podría afirmarse lo mismo por lo que hace al resto de ciudadanos, los que no hubiesen participado en el proceso. Con todo, como otras tesis consensualistas, la de Singer también defiende que estos últimos quedan obligados moralmente a obedecer las normas, pues, al margen de la participación, otros motivos concurren para justificar este deber de obediencia. En la teoría de Singer, la otra razón de peso es el mencionado compromiso justo que un orden democrático constituye ${ }^{8}$. En contra de la teoría del cuasi consentimiento se pronunciaron diversos autores que consideraron que la distinción entre aquel y el consentimiento no era sino una forzada diferenciación difícil de apreciar en la práctica, creada solo para sortear los problemas que planteaba este último al intentar justificar a su través la obediencia al derecho en un sistema democrático (Beran, 1987: 54 y 55; Nino, 1984: 233 y 240).

\section{NEOCONTRACTUALISMO Y OTRAS «RAZONES MORALES» DISTINTAS DEL CONSENTIMIENTO}

Las tesis anteriormente expuestas acuden a esquemas puramente procedimentales para justificar el deber de obediencia al derecho, siendo «lo decisivo aquí [...] los procedimientos para la obtención del consentimiento, más que el contenido del consentimiento en sí» (Falcón y Tella, 2002: 101). Otros autores contemporáneos han intentado justificar la obligación política - considerada como «el conjunto de obligaciones que tenemos como ciudadanos en relación con el Estado» (Fernández, 1986: 96 y 97) — - a partir de una reinterpretación del propio contrato social. Estas teorías neocontractualistas, principalmente representadas por Habermas y, sobre todo, por Rawls, partirán de unas premisas diferentes entre las que se incluye en efecto una revisión de la

8 Otros motivos secundarios justificarían también la obediencia. En relación con los ciudadanos que no participen en el procedimiento, su abstención podría ser un argumento que justificase la desobediencia al derecho. Desobedecer una ley generada en un procedimiento de toma de decisiones en el cual uno ha participado voluntariamente, afirma el autor, puede ser incorrecto, pero hay circunstancias «en las que estaría justificado que uno desobedeciera la misma ley si no ha participado en el sistema» (Singer, 1985: 68).

9 Para Patil (1988: 5) sería "la obligación que el individuo debe al Estado y viceversa» (cursivas añadidas). Falcón y Tella (2002: 99) aclara que «la obligación política supone el compromiso de obedecer toda una serie de ulteriores obligaciones derivadas sin requerir necesariamente un consenso caso por caso». 
articulación del pacto social; y en ellas se combina, además, este principio de legitimidad contractualista del sistema político con «la existencia de un Derecho que reconozca y garantice los derechos humanos fundamentales» (Fernández, 1986: 107) ${ }^{10}$.

La obra de Habermas ha tenido mucho predicamento en distintos ámbitos - la ética, la filosofía o la filosofía del derecho- y ha sido relevante asimismo en relación con la cuestión que aquí nos ocupa. En concreto, a través de la llamada ética del discurso se intentaría dar solución a la recurrente disensión entre moralidad autónoma y normatividad jurídica ${ }^{11}$. Se parte de la idea de que, fuera de todo plano puramente teórico, la ficción kantiana según la cual el legislador se limita a positivar un derecho moralmente fundado se revela del todo ineficaz como solución para aunar ambas categorías ${ }^{12}$. Con la introducción del principio del discurso se busca precisamente la coincidencia efectiva entre creador y destinatario de la ley. Hasta ahora el individuo solo había sido su destinatario; la ética del discurso aspira a justificar moralmente el acatamiento de la norma convirtiendo al individuo también en su creador.

La participación en «el discurso» según las normas propuestas por Habermas permitiría a los individuos consensuar las reglas comunes de convivencia y actuación, lo cual haría viable una producción políticamente autónoma del derecho. Se garantizaría así "una comprensión correcta del orden jurídico en su conjunto" (Habermas, 1998: 187) a los destinatarios del derecho, que podrían seguir ahora las normas por convicción, sobre la base de una razón moral de acatamiento.

En contra de las aportaciones de la ética del discurso a la obligación política se ha señalado que su entendimiento del consenso habría de conducir a un sistema totalizador ${ }^{13}$, que podría hacer desaparecer el «derecho a la

10 En realidad, el autor (Fernández, 1986: 107) atribuye esta combinación también a los autores contractualistas clásicos.

11 Para profundizar en los conceptos propios de esta teoría de Habermas, puede consultarse Baxter (2011: 9-59).

12 La idea que subyace al contrato originario es, según Kant (1999 [1793]: 268-269): «La de obligar a todo legislador a que dicte sus leyes como si pudieran haber emanado de la voluntad unida de todo un pueblo, y a que considere a cada súbdito, en cuanto que quiere ser ciudadano, como si hubiera votado por su acuerdo con una voluntad tal. Pues ahí está la prueba de la legitimidad de toda ley pública. Si se hubiera hecho de tal modo que resultara imposible a todo un pueblo otorgar su conformidad [...], entonces no es legítima».

13 Se ha puesto en duda el alcance práctico que esta teoría podría llegar a tener. La ética del discurso implica un consenso real sobre el contenido de la ley acordado por todos los destinatarios, frente a las propuestas tradicionales en las que el contenido es 
diferencia» (Young, 1990: 109, y Mouffe, 1999: 11 y ss. y 119 y ss.). Entiendo que esta afirmación, no obstante, puede hacerse del resultado de la ética comunicativa ideal, en la que el discurso derivará del diálogo entre todos los que han de acatar sus resultados, pero no del espacio existente entre el discurso moral ideal y la realidad democrática, en el que sí habría lugar al desacuerdo $\mathrm{y}$, consecuentemente, a una cierta disidencia frente a las normas ${ }^{14}$.

Son interesantes algunas versiones de la ética del discurso que se han propuesto para justificar la obediencia al derecho, como la que esboza el sistema democrático como un sucedáneo del discurso moral. Se superaría con ello el problema de la falta de unanimidad en la toma de decisiones y se posibilitaría un mayor margen para la disidencia frente a las normas y decisiones acordadas. Al estar legitimadas de manera imperfecta, la obligación de obediencia a estas pautas no sería absoluta, sino que tendría solo un carácter prima facie ${ }^{15}$.

Otra sugerente explicación sobre el deber moral de obediencia a las normas por medio de una revisión del pacto social se encuentra en la Teoría de la Justicia de Rawls (1979). Para garantizar que las leyes por las que la sociedad se rige sean justas, y por tanto dignas de ser obedecidas, se propone desde esta tesis una noción de justicia que debería ser el resultado del consenso de $\operatorname{todos}^{16}$. Lo novedoso es que tal consenso no es un acuerdo real, sino que se produce gracias a la denominada «posición original» en la que se encontrarían los individuos. Esta posición, que sería algo así como un punto de partida o un lugar de referencia, constituiría una guía natural para la intuición que permitiría que cualquiera pudiera adoptar siempre su

decidido por quien ha sido habilitado para ello por el consentimiento de los destinatarios futuros de la norma. Se duda, consecuentemente, de la posibilidad de «alcanzar una legislación única para todos los individuos a través de una multiplicidad de legisladores», o, en otras palabras, de «si las reglas de la comunicación ideal [...] garantizan siempre el consenso" (Gascón Abellán, 1990: 169-170). Véase también Tugendhat (1988: 127). En Cortina (1985: 219 y ss.) pueden encontrarse sistematizadas las distintas críticas a la teoría del discurso.

14 Algo parecido sucedía en la teoría de Singer (1985: 115 y ss.), donde primero se exponía el modelo ideal y a continuación se señalaban las deficiencias de su aplicación práctica. Como resultado de lo anterior, se llegaba también a la conclusión de la necesidad de flexibilizar el alcance de la obligación política en los actuales sistemas democráticos.

15 El alcance de la obligación dependerá de la desviación que se haya «producido respecto de las exigencias del discurso moral genuino» (Nino, 1984: 245).

16 En la tesis de Rawls (1979: 134), lo justo es «un conjunto de principios generales y universales en su aplicación, que han de ser públicamente reconocidos como tribunal final de apelación para jerarquizar las demandas conflictivas de las personas morales». 
perspectiva (la de la posición original) y conocer en cualquier momento los principios de la justicia. Se observará que la tesis consensualista de Rawls trata de evitar también la ficción del consensualismo clásico según la cual el legislador, al aprobar la ley, no hacía sino convertir la moral individual en la moral de todos. Para este autor, uno puede conocer la norma por sí solo si atiende a la realidad desde la mencionada perspectiva de la posición original (Rawls, 1979: 25 y 29-33).

También se han efectuado importantes ataques a esta teoría. Por lo que hace a la obligación moral de obediencia al derecho, concretamente, cabe destacar - como sucedía no solo con el consensualismo clásico, sino también con la teoría del discurso de Habermas - la crítica realizada sobre el carácter prácticamente absoluto de esta obligación, que se deduce de la premisa rawlsiana según la cual cumpliendo las normas se respondería al ideal propio de justicia (fairness) (Nozick, 1974: 160 y ss.; y Garzón Valdés, 1981: 88).

Dejando a un lado lo que se refiere al consentimiento o al aspecto formal, los autores contemporáneos ofrecen otras razones para justificar moralmente el deber de obedecer las normas de un ordenamiento democrático, todas ellas relacionadas con el valor objetivo que encarna tal sistema. Volviendo a Rawls, el autor otorga la máxima relevancia como justificación de esta obligación a la consecución de un ordenamiento justo. El «acuerdo original», de hecho, no tendría otro objeto que los principios de la justicia (Rawls, 1979: 24). También Habermas dota de importancia al aspecto sustantivo del ordenamiento jurídico, junto al procedimental. Sostiene que el objetivo de la introducción del principio democrático del discurso en el derecho es la reconstrucción de los derechos fundamentales, para que una asociación de personas "pueda entenderse como una comunidad jurídica de miembros libres e iguales»; el principio legitima además el propio poder político, pues este «sólo puede desplegarse a sí mismo a través de un código jurídico que haya sido institucionalizado en forma de derechos fundamentales» (Habermas, 1998: 199 у 201).

Por su parte, Singer se referiría, junto al cuasi consentimiento, al compromiso justo que un sistema democrático constituye:

La naturaleza del procedimiento de toma de decisiones es tal que permite que todos se abstengan de actuar según su propio juicio sobre determinados problemas, sin renunciar a más que el mínimo teórico al cual es esencial que cada uno renuncie con el fin de obtener los beneficios de una solución pacífica a las disputas $(1985: 41)^{17}$.

17 Sobre «la justicia como compromiso» en la obra de Singer, véase Beitz (1989: 78-84). 
En nuestro contexto, en fin, Peces-Barba (1988) destacaría tanto su carácter consensuado mayoritariamente como su naturaleza de compromiso justo, el contenido material de su ordenamiento jurídico, "coincidente, más que en ningún otro sistema, con la dignidad humana y con la realización de la autonomía o libertad moral» (1988: 163), y, finalmente, la presencia de cauces diversos a disposición del ciudadano para protestar frente a la norma injusta. Por tanto, las distintas razones morales de obediencia que habitualmente se aducen son reconducibles a dos: el clásico consenso y el contenido material propio de un sistema democrático ${ }^{18}$. En resumen, la posición doctrinal defendida de forma mayoritaria actualmente sostiene que la obediencia debida al derecho democrático, más allá del deber propiamente jurídico, tiene cierto carácter moral por su naturaleza consensuada y su contenido material objetivamente valorable.

Admitiéndose, pues, que existen razones morales para acatar la ley de un ordenamiento democrático, conviene aclarar enseguida que no es esta la motivación principal por la que la norma se obedece. Muy al contrario, habitualmente el acatamiento del deber legal responde a otros motivos más prácticos y ciertamente alejados de cualquier fundamento ético, como el simple automatismo ante la exigencia de un deber, o el temor a la sanción frente al eventual incumplimiento (conocida como razón prudencial); estas son motivaciones a las que se ha llamado, de hecho, razones típicas. Como señalara Prieto Sanchís (2007: 14), «es evidente que la mayor parte de las violaciones a la ley suelen responder al interés, el egoísmo o las pasiones, y no encierran ninguna pretensión de justificación moral». Por tanto, generalmente el fundamento ético será, todo lo más, una razón más entre las distintas motivaciones existentes a las que puede responder el perfeccionamiento del mandato legal ${ }^{19}$.

Existen, finalmente, otro tipo de razones que no pueden considerarse «motivos morales» de acatamiento de la norma democrática, pero que sí se sitúan, por así decir, en la órbita de lo ético. Se trata de los razonamientos para los que el cumplimiento del deber legal no llega a tener un fundamento moral, pero que sí acerca a fines que son éticamente valorables. Tal es el caso de la posición utilitarista que considera que el deber de obedecer las normas existe si del acatamiento resultan efectos provechosos tanto para quien ha de

18 Pueden consultarse Cámara Villar (1991: 20-21) o Díaz (1984: 105 y ss.; y 1965: 4 y ss.). Passerin D'entreves (1976: 28-30) distingue ocho tipos de actuación frente a la obediencia debida al derecho: obediencia consciente, obediencia formal, evasión oculta, obediencia pasiva, objeción de conciencia, desobediencia civil, resistencia pasiva y resistencia activa. 
cumplirlo como para el conjunto de la sociedad ${ }^{20}$; es el caso, asimismo, del argumento de la gratitud, según el cual «la asociación política reporta [...] beneficios que es de justicia agradecer; y cuando menos, esa gratitud debe hacerse patente a través de la obediencia al Derecho» (Gascón Abellán, 1990: $137)^{21}$; o también, en fin, el caso del argumento de la seguridad, que ha defendido el deber de obedecer las leyes por la seguridad que la observancia de las mismas proporciona ${ }^{22}$.

\section{LA INEXISTENCIA DE TODA «RAZÓN MORAL» PARA OBEDECER EL DERECHO DEMOCRÁTICO}

Hay quienes, en su aproximación a la cuestión de las razones por las que debe obedecerse la ley, han llegado a una conclusión distinta: la de la inexistencia de esa motivación moral. Desde esta perspectiva, otros argumentos válidos podrán justificar el acatamiento de la norma, pero nada tendrán que ver con lo ético. Suele citarse en este sentido a González Vicén, que expresaría esta postura con la controvertida afirmación de que «mientras que no hay un fundamento ético para la obediencia al Derecho, sí hay un fundamento ético absoluto para su desobediencia» (1979: 388). Estas palabras conducen indefectiblemente a otras, conocidísimas, de Henry D. Thoreau (1994 [1849]: 29-57), el primer teórico de la desobediencia civil, cuya cita constituye un clásico en toda reflexión sobre la cuestión que nos ocupa:

El ciudadano, ¿¿debe alguna vez, aunque sea por un momento, o en el mínimo grado, abdicar de su conciencia a favor del legislador? ¿Por qué entonces todos los hombres tienen conciencia? Creo que debemos ser hombres primero, y sólo después súbditos. No es tan deseable cultivar el respeto por el Derecho como por lo que es correcto. La única obligación que tengo derecho a asumir es hacer, en cualquier momento, lo que me parece correcto (Thoreau, 1994 [1849]: 54).

La obligación moral derivaría, pues, exclusivamente de la conciencia personal, que se encontraría completamente separada del plano jurídico. El

20 Goldman (1980: 13-31) ofrece una sugerente visión de la obligación de obedecer el derecho desde una perspectiva utilitarista en función de a quién vaya dirigida aquella.

21 Se parte de la idea de que «el Estado interviene en el entramado de las relaciones sociales facilitando ciertos bienes o servicios que de otra manera no estarían al alcance de individuos aislados» (Gascón Abellán, 1990: 137).

22 Hume (1982 [1751]: 49) afirmaría, desde esta perspectiva, que «el único fundamento del deber de obedecer consiste en la ventaja que proporciona a la sociedad el preservar la paz y el orden entre los hombres». 
derecho como expresión de la voluntad general —adoptada ya de forma unánime ya de forma mayoritaria - sería, desde esta perspectiva, una falacia: ni expresaría los intereses generales ni se formaría por la suma de imperativos de conciencias individuales. Como quiera que el derecho no contiene ni expresa imperativos morales, solo si coincide con lo que la propia conciencia exige $-\mathrm{y}$ solo por este motivo- existirá una razón ética para su cumplimiento ${ }^{23}$.

\section{LA JUSTIFICACIÓN DE LA DESOBEDIENCIA AL DERECHO EN UN ESTADO DEMOCRÁTICO}

\section{POSICIONES CONTRARIAS A LA JUSTIFICACIÓN DE LA DESOBEDIENCIA}

Cabría atribuir a la razón moral de acatamiento del derecho una entidad tal que no cupiese alegar excepción alguna frente a ella. Desde esta perspectiva, ninguna razón tendría más peso que la primera para justificar el incumplimiento de la norma.

Así ha sido defendido, en efecto, por algunos autores - los menosentre la doctrina científica. Tal es el caso de Rostow (1978), para quien, en una sociedad democrática, no solo el individuo presta su consentimiento al contrato social, comprometiéndose a obedecer la norma del Estado en el que libremente ha decidido permanecer, sino que la comunidad cuyo código abraza ese individuo es, en sí misma, una sociedad de consenso ${ }^{24}$. Consecuentemente, esta "obligación consentida» será absoluta y toda posibilidad de desobediencia al derecho habrá de rechazarse. Para exigir el cambio de una norma o denunciar el perjuicio que resulta de su observancia, por tanto, solamente podrá acudirse a las vías institucionalizadas. Como quiera que solamente si los procedimientos democráticos de acción política fallasen podría estar justificado el uso de medios ilegales para conseguir fines políticos, la desobediencia nunca estaría justificada, sensu contrario, en una sociedad democrática que funcionase correctamente en términos generales.

23 Otros autores que defenderían la inexistencia de un deber moral de obediencia al derecho son Legaz Lacambra (1956: 3-58) y Muguerza Carpintier (1986: 27 y ss.).

24 En palabras de Rostow (1978: 104): "Jefferson's standard — the standard of the American code of social justice- is drawn from two aspects of the idea of 'consent'. First, the individual has consented to the social contract: he has given his Platonic promise to obey the laws of the State where, as an adult, he has freely decided to stay. And second, the society to whose code he has adhered is itself a society of consent». 
En su teoría de la justicia, Rawls acepta que un grupo de ciudadanos incumpla una norma, pero únicamente en el supuesto hipotético de que se pretenda con ello que la mayoría admita un principio común de justicia. Se trataría de conducir a una mayoría «equivocada» hacia el parámetro correcto del que se ha desviado. La minoría infractora, por tanto, no actuaría movida por una convicción individual, sino por un principio universal de justicia, no habiendo lugar en esta tesis al incumplimiento de la norma (solo) por razón de la conciencia personal (Rawls, 1979: 320 y ss.) ${ }^{25}$.

Otros importantes politólogos estadounidenses contemporáneos, al abordar la justificación de la democracia como sistema político, sencillamente han orillado la cuestión que nos ocupa (entre otros, Dahl, 1999). No parece descabellado encuadrarlos entre quienes en principio no legitimarían la desobediencia al derecho democrático por razones morales. Con todo, las posturas que inicialmente rechazan cualquier tipo de disidencia frente al derecho democrático optan, como puede observarse, por abrir también un resquicio para la disidencia, para el caso de que la ley o medida que se quiere incumplir afecte, por así decir, a la conservación del sistema democrático (y ello con independencia de cómo se vea implicada la conciencia personal). Por tanto, en términos generales, las diversas teorías que abordan la cuestión de la obediencia al derecho acaban justificando de uno u otro modo alguna forma de incumplimiento de la ley.

\section{JUSTIFICACIÓN DE LA DESOBEDIENCIA POR RAZONES MORALES}

De conformidad con cuanto antecede, mayoritariamente se acepta que la observancia del derecho democrático responde, entre otras razones, a un imperativo ético, por cuanto es expresión de valores morales tales como la tendencia al consenso, la justicia o la equidad. Sin embargo, también de forma mayoritaria se admite que dicho imperativo no es absoluto, sino solamente una obligación prima facie que puede ser vencida por otra, por un mandato personal que se imponga moralmente en un sentido distinto. Dos tipos de obligación moral podrían, pues, distinguirse: la que forma parte de la norma democrática (obligación moral prima facie) y la moral stricto sensu (obligación moral fuerte), que podrá coincidir con lo que la norma disponga pero que también podrá no hacerlo, por ser un imperativo autónomo que se origina exclusivamente en la conciencia «autolegisladora» ${ }^{26}$.

25 Para justificar la desobediencia, afirmaría Rawls, «uno no apela a principios de moralidad personal ni a doctrinas religiosas [...] Invoca en cambio la concepción comúnmente compartida de la justicia que fundamenta el orden político» (1979: 333).

26 Esta diferenciación puede encontrarse en Fernández García (1987: 109) y Gascón Abellán (1990: 128). 
Por tanto, aunque puedan darse razones éticas para el cumplimiento del derecho, una "genérica positiva valoración de las instituciones jurídico-políticas democráticas en modo alguno exige absoluta e incondicionada aceptación de ellas» (Díaz, 1984: 95), ya que "el análisis llevado a cabo por una persona individual puede estar más cerca de la justicia y de la verdad que una opinión, una creencia o un juicio expresado por más o menos amplias mayorías» (Díaz, 1984: 99). Peces-Barba afirmaría, en este sentido, que aunque en una sociedad democrática existen buenas razones morales para obedecer el derecho, cuando un sistema aparentemente democrático «impide que cada uno pueda pretender realizar su autonomía moral, con normas que dificulten el dinamismo de la libertad, la desobediencia está justificada moralmente» (1988: 162) ${ }^{27}$.

Es difícil no coincidir con esta posición mayoritaria. En mi opinión, en efecto, si hay una cierta obligación moral de acatamiento del derecho democrático por ser justo y respetuoso de la dignidad humana, su desobediencia puede estar éticamente más justificada cuando no lo sea. Fácilmente se entiende que el debate sobre esta cuestión se avivase sobre todo cuando en sistemas teóricamente democráticos comenzaron a adoptarse políticas o leyes que eran objetivamente injustas, tales como las aprobadas durante el régimen nacionalsocialista en Alemania o el del apartheid en Sudáfrica.

Sin duda este asunto ha cobrado recientemente una gran importancia en nuestro contexto. Salvando todas las distancias, en España la controversia en torno al deber de obedecer la ley se ha reavivado ante la llamada al rechazo de algunas normas o políticas consideradas socialmente inicuas desde movimientos ciudadanos como la Plataforma Antidesahucios o el 15-M. Así lo evidencia la reciente literatura científica sobre el particular elaborada desde las más variadas aproximaciones $^{28}$.

\section{PRECISIONES CONCEPTUALES}

La actualidad de este debate invita a perfilar algunos aspectos sobre la disidencia ética frente a la norma democrática, en el bien entendido de que, $a b$ initio, en cierto modo estamos obligados moralmente a obedecer el derecho

27 En sentido análogo, Cámara Villar (1991: 20-21) sostiene que cualquier ciudadano, en principio moral y jurídicamente obligado «a observar los deberes u obligaciones establecidos por el Derecho, puede verse confrontado con éste, y justificada su actitud desobediente».

28 Puede mencionarse, desde la perspectiva jurídico-constitucional, a Pisarello Prados (2013); una reflexión sociológica se encuentra en Rodríguez López (2014); una interesante aproximación iusfilosófica a la cuestión puede encontrarse en De Lucas Martín (2014); y otra «puramente» filosófica, finalmente, en Acinas Vázquez (2013). 
democrático. Moralmente, porque es evidente que jurídicamente lo estamos desde que la prescripción forma parte del ordenamiento jurídico. Antes de profundizar en los distintos tipos de disidencia, conviene dejar claro que en ningún momento se enjuicia el alcance del deber legal desde la perspectiva estrictamente jurídica, pues es claro que tal deber, desde que existe, obliga. Se ha querido abordar aquí su alcance efectuando una aproximación más ética a la cuestión, y esta reflexión, por una parte, nos ha permitido concluir que el propio deber legal tiene un trasfondo ético en un sistema democrático $y$, por otra, nos conduce a interesarnos — ahora sí, jurídicamente- sobre cómo el ordenamiento pueda o deba reaccionar ante la oposición a una norma o política cuando el rechazo tiene ese trasfondo.

Desde una perspectiva puramente conceptual, conviene distinguir dos tipos de desobediencia éticamente motivada, atendiendo al criterio teleológico $^{29}$. Si la ley se desobedece precisamente para modificarla porque se la considera socialmente injusta, nos encontraríamos ante un supuesto de desobediencia civil. En cambio, si lo que se pretende es evitar el cumplimiento de un deber que entra en conflicto con la sola conciencia individual, será un caso de objeción de conciencia.

El desobediente civil acepta con carácter general el orden establecido, pero aspira al cambio de una norma o política que considera socialmente inaceptable según ciertos valores - comunes - de justicia. Por ello desea atraer la atención de la ciudadanía, de los medios de comunicación y, sobre todo, de los poderes públicos para que se produzca la derogación o modificación de la norma desobedecida. En coherencia con cuanto antecede, la categoría suele presentar un carácter excepcional, público, colectivo, pacífico en términos generales, y suele ir acompañada de la «aceptación del castigo», esto es, de la aceptación de la consecuencia aparejada al incumplimiento ${ }^{30}$;

29 Existen otros tipos de disidencia que responden a una motivación ideológica, pero solo interesan estas dos, al ser las únicas que se caracterizan por el criterio de la lealtad constitucional, entendido como el «respeto a las reglas del juego democrático». Así lo entienden de forma minoritaria Gascón Abellán (1990: 45) o Peces-Barba Martínez (1978: 237-238) frente a otros autores —como Garzón Valdés (1981), Raz (1982: 324) o Malem Seña (1988: 48 y 60) — cuyas clasificaciones de los tipos de desobediencia ideológicamente motivada frente a la norma responden a un concepto distinto de lealtad constitucional.

30 En su «Carta desde la cárcel de Birmingham» (citada en Bedau, 1969: 78-79), M. Luther King afirmaría, en relación con este aspecto, que «un individuo que infringe una ley que su conciencia le dice que es injusta, y de buena gana acepta la penalidad de quedarse en la cárcel para hacer que la comunidad tome conciencia de su injusticia, está expresando, en realidad, un supremo respeto por la ley». 
pero, sobre todo, indefectiblemente ostenta una característica: la de ser un acto ilegal ${ }^{31}$.

Interesa dejar claro, en este sentido, que la desobediencia civil está necesariamente fuera del derecho. No pueden compartirse las posiciones doctrinales, ciertamente excepcionales, que defienden el posible carácter jurídico de esta disidencia ${ }^{32}$. Cuestión distinta será que el acto desobediente sea valorado socialmente de forma positiva y en última instancia acabe teniendo efectos propiamente jurídicos. Concretamente, Garzón Valdés se refiere a la desobediencia civil como «una estrategia para obtener la declaración judicial de inconstitucionalidad, [aunque] el procedimiento judicial se inicia a través de acciones que prima facie parecen ser antijurídicas» (1981: 91). Al margen debe dejarse también el llamado "derecho de resistencia», constitucionalizado en el artículo 20.4 de la Ley Fundamental de Bonn, según el cual «contra cualquiera que intente eliminar este orden todos los alemanes tienen el derecho de resistencia cuando no fuere posible otro recurso». En resumidas cuentas, la desobediencia civil puede estar moralmente justificada, pero su propia naturaleza exige que sea un acto contrario a derecho. La pretensión de regulación de un supuesto de desobediencia civil no deja de ser, en mi opinión, una contradicción in terminis.

Una categoría distinta de disidencia ética, según se ha expuesto, la constituye la objeción de conciencia, que a diferencia de la anterior no tiene por qué existir exclusivamente fuera del derecho. También aquí interesa aclarar lo relativo a la naturaleza de la categoría incidida, aunque en este caso la doctrina científica se encuentra más dividida. Podrá hablarse de objeción de conciencia «en términos jurídicos» cuando la misma esté reconocida como un derecho. Ahora bien, según creo, la objeción no forma parte del ordenamiento en el sentido defendido por un amplio sector doctrinal que la considera una manifestación del derecho fundamental a la libertad de conciencia - reconocida de una u otra forma en todo texto constitucional que se precie de serlo- - Y es que con esta afirmación se legitimaría el incumplimiento de cualquier deber jurídico por el solo hecho de ser contrario a las convicciones personales. La objeción, según lo entiendo, formará parte del ordenamiento jurídico únicamente cuando el supuesto concreto haya sido reconocido como un

31 Se han ofrecido diversas definiciones de la desobediencia civil, que se refieren con más o menos énfasis a las distintas notas características arriba mencionadas. Véanse Gascón Abellán (1990: 52); Garzón Valdés (1981: 82-85); Rawls (1979: 332); Rodríguez Paniagua (1982: 97-99) o Wellman (1982: 30-31).

32 Una justificación en esta dirección se encuentra en Ugartemendia Eceizabarrena (1999: 213-214 y 279-288) y Zwiebach (1975: 147). 
derecho por la ley. Un derecho de rango legal, legitimado por el legislador democrático en desarrollo de un derecho fundamental, de cuyo contenido constitucionalmente declarado no formaría parte una pretendida facultad genérica de objetar a las obligaciones jurídicas (Gómez Abeja, 2016: 247-250) ${ }^{33}$.

No conviene confundir estas dos categorías. Es frecuente que quienes defienden que existe un derecho a incumplir la norma invocando el derecho fundamental a la libertad de conciencia se refieran a Thoreau, Gandhi, o Martin Luther King, y al hacerlo confunden - ¿deliberadamente? - los distintos tipos de disidencia ética. Parece desacertado traer a colación las loables actitudes de aquellos para justificar el incumplimiento de cualquier deber por razones ideológicas exclusivamente personales, y por quien no está dispuesto a asumir consecuencia alguna y sí lo está para lesionar de este modo el legítimo interés de un tercero. No toda disidencia puede valorarse de la misma manera. Resultan preocupantes casos como el de los jueces que se oponían a tramitar expedientes matrimoniales de personas del mismo sexo, por ser contraria a sus creencias la ley que legalizó en 2005 el matrimonio homosexual en España; el de los médicos de atención primaria que se han negado a informar a una paciente embarazada de sus derechos ante la posible interrupción de su embarazo, por lesionar su conciencia la Ley Orgánica 2/2010, de 3 de mayo, de Salud Sexual y Reproductiva y de Interrupción Voluntaria del Embarazo ${ }^{34}$; o, en fin, el del farmacéutico que, invocando las mismas razones, ha rehusado la dispensa de medicamentos anticonceptivos ${ }^{35}$.

No existiendo la objeción como derecho fundamental, la única posibilidad de ejercerla será la que brinde el legislador atendiendo a ciertos criterios que podrían orientarlo sobre la idoneidad de prever una excepción legal al cumplimiento de un deber. En un Estado que se precie de ser realmente democrático conviene ofrecer a los ciudadanos la posibilidad de denunciar e

33 Véanse también: Barrero Ortega (2006: 410 y ss.), López Castillo (2001: 51), MartínRetortillo Báquer (1999: 193) y Murillo de la Cueva (2011: 21). Otra posición sobre la naturaleza jurídica de la objeción de conciencia se encuentra en Escobar Roca (1993: 167 y ss.).

34 Sobre el derecho a la objeción de conciencia que la Ley Orgánica 2/2010 reconoce al personal sanitario, puede consultarse Capodiferro Cubero (2015).

35 Debe señalarse, a pesar de lo que aquí se argumenta, que el Tribunal Constitucional ha otorgado recientemente el amparo a un farmacéutico que había sido sancionado por la Administración por incumplir su obligación de disposición de la "píldora poscoital», para la que no había prevista excepción legal alguna. Se trata de la controvertida STC 145/2015, en la que el Alto Tribunal consideraría que se había lesionado la libertad del artículo 16.1 CE del recurrente. Un exhaustivo análisis de esta sentencia se encuentra en Barrero Ortega (2016). 
incluso esquivar la norma que atente contra las propias creencias y una opción será hacerlo promocionando la libertad de conciencia mediante la legitimación de supuestos concretos de objeciones. Pero lo que no puede hacerse es utilizar argumentos positivos propios de la desobediencia civil para justificar la objeción de conciencia y atribuirle toda suerte de facultades exorbitantes al catalogarla como un derecho fundamental.

Volviendo a la desobediencia civil, en ella no cabe - ya se ha dichojustificación jurídica en ningún caso. En cuanto a la justificación moral, no cualquier incumplimiento de la norma inspirado en unos pretendidos valores comunes de justicia o equidad estará justificado ni siquiera desde esa perspectiva ética. Ello dependerá de circunstancias tales como el carácter esencialmente pacífico de la actitud desobediente. Más genéricamente, se habla del respeto a la lealtad constitucional y al orden establecido ${ }^{36}$. Puede afirmarse, en conclusión, que no toda actitud de incumplimiento que busque una mejora social estará moralmente justificada, incluso aunque se esté dispuesto a aceptar la sanción aparejada al incumplimiento. Aunque formal e inicialmente pueda resultar estimable la disidencia de quien busca la derogación o cambio de cierta norma socialmente injusta, el recurso a la fuerza o el incumplimiento generalizado - $\mathrm{y}$ no puntual o excepcional - de las leyes puede conducir a que deje de estar éticamente justificada la conducta del desobediente civil.

\section{CONCLUSIONES}

Ha de aceptarse — así lo entiende la mayor parte de la doctrina científicala existencia de una obligación moral prima facie de obediencia a las leyes de un sistema democrático, en tanto que este se define por su valor objetivo tanto de carácter formal — por su origen consensuado- como material — por su fundamento en ciertos principios que deberían respetarse en cualquier sociedad.

Debe aceptarse también —a partir de la distinción entre la obligación moral fuerte, que tiene su origen exclusivamente en la conciencia personal, y la obligación moral débil, aparejada al mandato jurídico— que la desobediencia al derecho por razones morales también puede estar justificada, pues podría concurrir un imperativo de la conciencia personal frente a la obligación moral prima facie integrada en el deber jurídico.

Dentro del espectro de los distintos tipos de disidencia ética frente a la norma, al derecho democrático le interesan esencialmente dos categorías que

36 En el sentido defendido por Prieto Sanchís (1984: 47) y Peces-Barba Martínez (1983: 72). 
no conviene confundir y que pueden distinguirse atendiendo al criterio teleológico: la desobediencia civil, que persigue cambiar la norma socialmente injusta, y la objeción de conciencia, con la que solo se pretende esquivar el conflicto de conciencia individual que la norma provoca.

La primera podrá estar moralmente justificada — dependerá de que se respete con carácter general la legalidad vigente y de su carácter esencialmente pacífico- pero nunca estará legitimada por el derecho. La objeción de conciencia, más allá de la justificación moral, sí podrá formar parte del ordenamiento jurídico, pero solamente como un derecho de rango legal (no fundamental) y siempre que el legislador reconozca el supuesto concreto de objeción como un derecho.

\section{Bibliografía}

Acinas Vázquez, J. C. (2013). Notas acerca de la desobediencia civil. Laguna, 33, 77-98.

Barrero Ortega, A. (2006). La libertad religiosa en España. Madrid: Centro de Estudios Políticos y Constitucionales.

- (2016). La objeción de conciencia farmacéutica. Revista de Estudios Políticos, 172, 83-107. Disponible en: https://doi.org/10.18042/cepc/rep.172.03.

Baxter, H. (2011). Habermas: The discourse theory of law and democracy. Stanford: Stanford Law Books. Disponible en: https://doi.org/10.11126/stanford/9780804769129.001.0001.

Bedau, H. A. (ed.). (1969). Civil disobedience: Theory and practice. Nueva York: Pegasus.

Beitz, C. R. (1989). Political Equality, An Essay in Democratic Theory. Princeton: Princeton University Press.

Beran, H. (1987). The consent theory for political obligation. Worcester: Routledge.

Cámara Villar, G. (1991). La objeción de conciencia al servicio militar: las dimensiones constitucionales del problema. Madrid: Civitas.

Capodiferro Cubero, D. (2015). La objeción de conciencia a la interrupción del embarazo. Madrid: Centro de Estudios Políticos y Constitucionales.

Cortina, A. (1985). Razón comunicativa y responsabilidad solidaria. Salamanca: Sígueme.

Dahl, R. A. (1999) [1998]. La democracia: una guí para los ciudadanos. Madrid: Taurus.

De Lucas Martín, F. J. (2014). Sobre desobediencia y democracia. La hora de la ciudadanía. Derechos y Libertades, 31, 57-76.

Díaz, E. (1965). La justificación de la democracia. Sistema, 66, 3-24.

- (1984). De la maldad estatal y la soberanía popular. Madrid: Debate.

Escobar Roca, G. (1993). La objeción de conciencia en la Constitución española. Madrid: Centro de Estudios Constitucionales.

Falcón y Tella, M. J. (2002). La obligación política de obediencia del individuo. Revista de Estudios Políticos, 115, 99-110.

Fernández García, E. (1986). Neocontractualismo y obediencia al Derecho. Anuario de Derechos Humanos, 4, 87-110. (1987). La obediencia al Derecho. Madrid: Civitas.

Garzón Valdés, E. (1981). Acerca de la desobediencia civil. Sistema, 42, 79-92. 
Gascón Abellán, M. (1990). Obediencia al Derecho y objeción de conciencia. Madrid: Centro de Estudios Constitucionales.

Goldman, A. (1980). The obligation to obey the law. Social Theory and Practice, 6 (1), 13-31. Disponible en: https://doi.org/10.5840/soctheorpract19806115.

Gómez Abeja, L. (2016). Las objeciones de conciencia. Madrid: Centro de Estudios Políticos y Constitucionales.

González Vicén, F. (1979). Estudios de Filosofía del Derecho. Tenerife: Universidad de La Laguna.

Habermas, J. (1998) [1992]. Facticidad y validez. Madrid: Trotta.

Hume, D. (1982) [1751]. Una investigación sobre los principios de la moral. En D. Hume. De la moral y otros escritos. Madrid: CEC.

Kant, I. (1999) [1793]. Sobre el tópico: esto puede ser correcto en teoría, pero no vale para la práctica. En I. Kant. En defensa de la Ilustración. Barcelona: Alba.

Legaz Lacambra, L. (1956). Notas para una teoría de la obligación política. Revista de Estudios Políticos, 85, 3-58.

López Castillo, A. (2001). Algunas consideraciones en torno a la Carta de Derechos Fundamentales de la UE. Revista de Estudios Políticos, 113, 43-74.

Malem Seña, J. F. (1988). Concepto y justificación de la desobediencia civil. Barcelona: Ariel.

Martín-Retortillo Báquer, L. (1999). El marco normativo de la libertad religiosa. En A. Motilla de la Calle et al. La libertad religiosa a los veinte años de su Ley Orgánica (pp. 167-215). Madrid: Ministerio de Justicia.

Mouffe, C. (1999). El retorno de lo politico: comunidad, ciudadanía, pluralismo, democracia radical. Barcelona: Paidós.

Muguerza Carpintier, J. (1986). La obediencia al Derecho y el imperativo de la disidencia. (Una intrusión en un debate). Sistema, 70, 27-40.

Murillo de la Cueva, P. L. (2011). Objeción de conciencia y desobediencia civil. En L. Prieto Sanchís (coord.). Actas de los seminarios sobre objeción de conciencia y desobediencia civil (pp. 15-26). Madrid: Fundación Ciudadanía y Valores.

Nino, C. S. (1984). Ética y derechos humanos: un ensayo de fundamentación. Buenos Aires: Paidós.

Nozick, R. (1974). Anarchy, State and utopia. New York: Basic Books.

Partridge, P. H. (1971). Consent and consensus. London: Macmillan.

Passerin D’entreves, A. (1976) [1972]. Legitimidad y resistencia. Sistema, 13, $27-34$.

Patil, V. T. (1988). Mahatma Gandhi and the Civil Disobedience Movement (A study in the Dynamics of Mass Movement). Delhi: Renaissance Publishing House.

Peces-Barba Martínez, G. (1978). Reflexiones sobre Derecho y poder. En G. Peces-Barba Martínez (ed.). Libertad, Poder, Socialismo (pp. 219-239). Madrid: Civitas.

- (1983). Derechos fundamentales. Madrid: Universidad Complutense.

— (1988). Desobediencia civil y objeción de conciencia. Anuario de Derecho Humanos, 5, 159-176.

Pérez Luño, A. E. (1991). ¿Qué deber? Consideraciones sobre el deber de obediencia al Derecho con especial referencia a la teoría de H. L. A. Hart. En J. Delgado Pinto et al. (eds.). Obligatoriedad y Derecho (pp. 381-406). Oviedo: Universidad de Oviedo.

Pérez Royo, J. (2014). Curso de Derecho Constitucional. Madrid: Marcial Pons. 
Pisarello Prados, G. (2013). El proceso constituyente y la rebelión de los nadie. El viejo topo. 306-307, 41-44.

Plamenatz, J. P. (1970) [1938]. Consentimiento, libertad y obligación política. México DF: Fondo de Cultura Económica.

Prieto Sanchís, L. (1984). La objeción de conciencia como forma de desobediencia al Derecho. Sistema, 59, 41-62.

- (2007). Desobediencia civil y objeción de conciencia. En I. Sancho Gargallo (dir.). Objeción de conciencia y función pública (pp. 13-62). Madrid: Consejo General del Poder Judicial.

Rawls, J. (1979). Teoría de la Justicia. México DF: Fondo de Cultura Económica.

Raz, J. (1982) [1979]. La autoridad del Derecho: ensayos sobre Derecho y moral. México DF: Universidad Autónoma de México.

Rodríguez López, E. (2014). Entre procesos constituyentes: del régimen de la Transición a la nueva democracia. Éxodo, 123, 22-30.

Rodríguez Paniagua, J. M. (1982). La desobediencia civil. Revista Española de Derecho Constitucional, 5, 95-114.

Rostow, E. V. (1978). The ideal in Law. Chicago: University of Chicago Press.

Rousseau, J. J. (2004) [1762]. El contrato social. Madrid: Akal.

Siegler, F. (1968). Plamenatz on Consent and Obligation. Philosophical Quarterly, 18 (72), 256-261. Disponible en: https://doi.org/10.2307/2218563.

Simmons, A. J. (1976). Tacit consent and political obligation. Philosophy and public affairs, 5 (3), 274-291.

- (1981). Moral Principles and Political Obligations. Princeton: Princeton University Press. Singer, P. (1985) [1973]. Democracia y desobediencia. Barcelona: Ariel.

Thoreau, H. D. (1994) [1849]. Desobediencia civily otros escritos. Madrid: Tecnos.

Tugendhat, E. (1988). Problemas de la ética. Barcelona: Crítica.

Tussman, J. (1960). Obligation and the body politic. New York: Oxford University Press.

Ugartemendia Eceizabarrena, J. I. (1999). La desobediencia civil en el Estado Constitucional Democrático. Madrid: Marcial Pons.

Wellman, C. (1982). Morales y éticas. Madrid: Tecnos.

Young, I. M. (1990). Justice and the politics of difference. Princeton: Princeton University Press. Zwiebach, B. (1975). Civility and Disobedience. Cambridge: Cambridge University Press. 